\title{
27. INFERENCES ON THE MAGNETIC DOMAIN STATE OF LEG 37 BASALTS
}

\author{
G.S. Murthy, E.R. Deutsch, and R.R. Pätzold, Geomagnetic Research Laboratory, \\ Physics Department, Memorial University of Newfoundland, St. John's, Canada
}

\section{INTRODUCTION}

We report results of the magnetic experiments conducted on samples from Leg 37 of the Deep Sea Drilling Project. The objective of the experiments is to infer the domain state of the magnetic minerals of the oceanic Layer 2 basalts. The following magnetic properties were studied: Rayleigh loops in low fields; high-field hysteresis parameters at room temperature and at liquid nitrogen temperature; temperature dependence of low-field susceptibility $k$ ( $k-T$ curves) and of high-field magnetic moment ( $M-T$ curves); and the comparison of $\mathrm{AF}$ demagnetization characteristics of natural remanence with those of isothermal saturation remanence in the way suggested by Lowrie and Fuller (1971). Samples were available from Hole 332B and Sites 334 and 335. Results of each experimental study are reported individually and a brief summary with conclusions is given.

\section{EXPERIMENTAL RESULTS}

\section{Rayleigh Loops}

Hysteresis loops in a field of 10 oe, usually called Rayleigh loops, were obtained using apparatus described by Radhakrishnamurty et al. (1969). Radhakrishnamurty and Sastry (1970) observed open or constricted Rayleigh loops in many, especially Cenozoic, basalts and attributed them to the presence of interacting "very fine single-domain grains" with relaxation times of the order of experimental time, i.e., grains that lie in the superparamagnetic (SP) size range. Although Rayleigh loops may arise in other ways, e.g., from large multidomain (MD) grains, the loops in that case should have $B H_{c} / A$ values in the range 0.03 to 0.1 (Néel, 1955), where $A$ and $B$ are the Rayleigh constants and $H_{c}$ is the bulk coercivity; such loops are too narrow to be observed with standard equipment. Radhakrishnamurty and Sastry point out that, since the $B H_{c} / A$ values $(\sim 20)$ for their samples showing wide loops exceed the theoretical MD values by two or three orders of magnitude, the actual loops are unlikely to be due to MD grains, a conclusion supported by Néel (1970).

Based on low-field hysteresis, the samples available from Leg 37 can be grouped as follows (mainly as in Deutsch and Pätzold, 1975):

Type I: Open Rayleigh loops: only one sample (332B11-1) showed this.

Type II. For all other samples, the Rayleigh-loop tracer produced a straight line; i.e., Rayleigh loops were absent. For most of these samples the slope of this line was relatively small, corresponding to low initial susceptibility, $k$ (Type IIa). However, for five samples (332B-35-1, 4-7 cm; 332B-35-4, 23-30 cm; 332B-37-1,
$126-128 \mathrm{~cm}$; 332B-37-2, 102-105 cm; and 334-26-2, 4-7 $\mathrm{cm})$ the slope and hence $k$ are relatively large (Type IIb). As will be seen, subtypes IIa and IIb are distinct also in their high-field hysteresis behavior.

\section{High-field Hysteresis}

Hysteresis loops were also obtained in fields of the order of 1200 oe using apparatus described by Likhite et al. (1965). Dunlop (1969), Radhakrishnamurty et al. (1971), and Lowrie and Fuller (1971), among others, have all recognized the importance of hysteresis studies in knowing the domain structure of the magnetic grains in a rock. Radhakrishnamurty et al. (1972) have successfully extended hysteresis measurements of rocks to liquid nitrogen temperature, and, based on earlier theoretical and experimental work by Bickford (1950), Bean (1955), and Morrish and Watt (1958), have developed "magnetic granulometric" experimental procedures which are quite useful in delineating the single- or multidomain character of samples and in some cases to identify the magnetic minerals in them. Using very similar procedures, we have obtained hysteresis loops for some samples of Leg 37 basalts both at room and liquid nitrogen temperatures. The results for coercivity $\left(H_{c}\right)$ and relative remanence $\left(J_{s} \mathbf{r} / J_{r}\right)$ at both $20^{\circ} \mathrm{C}$ and $-196^{\circ} \mathrm{C}$ are listed in Table 1.

\section{k-T and M-T Curves}

Variation of susceptibility with temperature in the range of $-196^{\circ} \mathrm{C}$ to $650^{\circ} \mathrm{C}$ was measured with an a.c. bridge (Pätzold, 1972) in a low field of $0.31 \mathrm{oe}$. The $M$ $T$ curves were obtained in air in fields of $1300 \mathrm{oe}$, using apparatus described by Deutsch et al. (1971). Results are listed in Table 1.

\section{AF Demagnetization Characteristics and the Lowrie- Fuller Test}

In Lowrie and Fuller's (1971) test for distinguishing multidomain from single-domain carriers of remanence, use is made of the distinctive AF demagnetization characteristics of the two domain states. We have applied this test to eight samples of Leg 37 basalts. First, we demagnetized the NRM of the samples up to 900 oe peak field (Table 2). The NRM is quite stable, the directional change being small in all cases, with median destructive fields of the order of 300 oe. The samples were then given IRM in fields of 8600 oe, after which this IRM was demagnetized in alternating fields, again to 900 oe. The results are presented in Table 2 and, for two representative samples, are shown in Figure 1. For all the eight samples, this test showed that the remanence is carried by pseudo singledomain (PSD) (Johnson et al., 1975) or single-domain grains. 
TABLE 1

Summary of Experimental Results

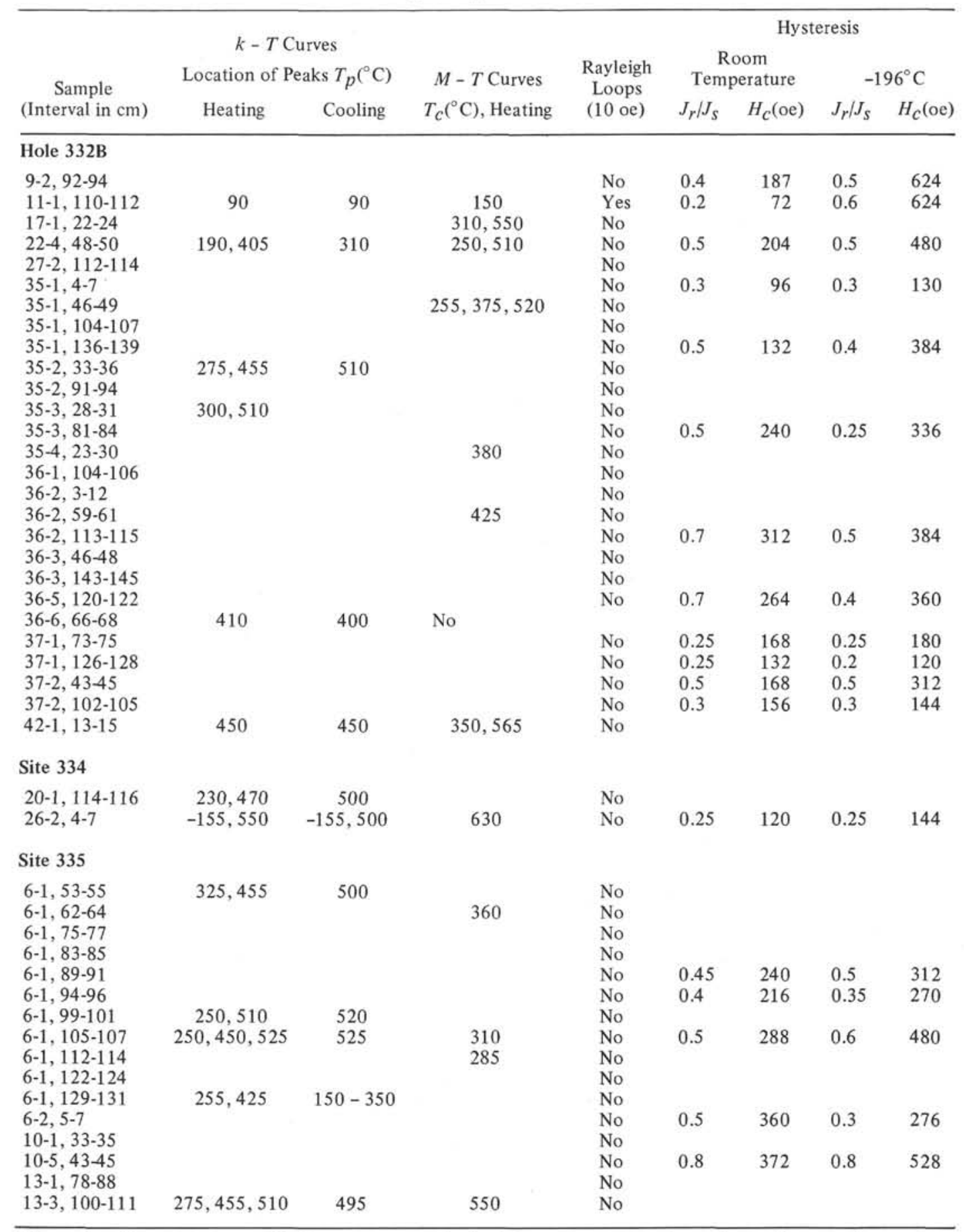

Note: $T_{c}=$ True or apparent Curie temperature obtained from temperature dependence of magnetic moment $(M-T$ curves $)$ in 1300 oe, using powdered samples; $J_{r} / J_{S}=$ Ratio of remanence to saturation magnetization in 1200 peak oe; $H_{C}=$ Coercivity.

\section{DISCUSSION}

First we discuss two samples (332B-11-1 and 334-262) that showed quite exceptional behavior compared with all others. For example, they had the smallest Koenigsberger ratios $\left(Q_{n}=2.1,1.5\right)$ and largest $k$ values $\left(1.67 \times 10^{-3}, 4.22 \times 10^{-3}\right.$ Gauss/oe $)$; in the other samples, $Q_{n}$ tended to be one or two orders of magnitude larger, and $k$ one order of magnitude less.

\section{Sample 332B-11-1 (Figure 2)}

This was the only sample showing an open Rayleigh loop (Type 1). The $k-T$ curves also are unique, with a spectacular peak on heating at $90^{\circ} \mathrm{C}$, followed by very low $k$ values and a lowered peak on cooling. As the loop parameters are similar to values reported by Radhakrishnamurty and Sastry (1970) for open Rayleigh loops, we attribute our loops to the presence 
TABLE 2

Lowrie-Fuller Test Results

\begin{tabular}{|c|c|c|c|c|c|c|c|c|c|c|c|c|c|c|c|c|c|c|}
\hline \multirow{3}{*}{$\begin{array}{c}\text { Field } \\
\text { (peak oe) }\end{array}$} & \multicolumn{5}{|c|}{$332 \mathrm{~B}-9-2,92-94 \mathrm{~cm}$} & \multicolumn{7}{|c|}{$332 \mathrm{~B}-35-1,136-139 \mathrm{~cm}$} & \multicolumn{6}{|c|}{$332 \mathrm{~B}-36-2,113-115$} \\
\hline & \multicolumn{3}{|c|}{ NRM } & \multicolumn{2}{|r|}{ IRM } & \multirow[b]{2}{*}{$J / J_{O}$} & \multicolumn{3}{|c|}{ NRM } & \multicolumn{3}{|c|}{ IRM } & \multicolumn{3}{|c|}{ NRM } & \multicolumn{3}{|c|}{ IRM } \\
\hline & $D$ & $I$ & $J / J_{O}$ & $D$ & $I$ & & $D$ & $I$ & $J / J_{O}$ & $D$ & $I$ & $J / J_{O}$ & $D$ & $I$ & $J / J_{O}$ & $D$ & $I$ & $J / J_{O}$ \\
\hline NRM & 177 & -2 & 1.00 & 0 & 0 & 1.00 & 343 & -23 & 1.00 & 0 & -2 & 1.00 & 230 & 8 & 1.00 & 6 & 3 & 1.00 \\
\hline 25 & 175 & -5 & 0.99 & 0 & 0 & 0.95 & 338 & -32 & 0.95 & 0 & -2 & 0.86 & 230 & 8 & 1.00 & 5 & 3 & 0.98 \\
\hline 50 & 174 & -9 & 0.94 & 0 & 0 & 0.79 & 338 & -39 & 0.97 & 0 & -3 & 0.54 & 230 & 8 & 1.00 & 5 & 3 & 0.93 \\
\hline 100 & 173 & -10 & 0.80 & 0 & 1 & 0.50 & 339 & -41 & 0.70 & 0 & -3 & 0.21 & 230 & 8 & 0.98 & 5 & 3 & 0.79 \\
\hline 150 & 173 & -12 & 0.66 & 0 & 1 & 0.29 & 343 & -43 & 0.52 & 0 & -4 & 0.14 & 230 & 7 & 0.92 & 5 & 3 & 0.65 \\
\hline 200 & 175 & -12 & 0.47 & 0 & $i$ & 0.18 & 338 & -23 & 0.39 & 359 & -4 & 0.10 & 230 & 7 & 0.77 & 5 & 3 & 0.52 \\
\hline 250 & 178 & -14 & 0.31 & 0 & 1 & 0.12 & 339 & -43 & 0.35 & 359 & -4 & 0.08 & 230 & 6 & 0.63 & 5 & 3 & 0.41 \\
\hline 300 & 175 & -8 & 0.19 & 0 & i & 0.09 & 336 & -44 & 0.27 & 359 & -4 & 0.07 & 231 & 6 & 0.53 & 5 & 3 & 0.33 \\
\hline 400 & 198 & -3 & 0.17 & 0 & 1 & 0.05 & 339 & -38 & 0.19 & 0 & -4 & 0.05 & 230 & 3 & 0.36 & 5 & 3 & 0.22 \\
\hline 600 & 246 & -42 & 0.07 & 0 & 1 & 0.03 & 338 & -44 & 0.11 & 359 & -4 & 0.03 & 231 & 8 & 0.17 & 6 & 2 & 0.11 \\
\hline 750 & - & - & - & 0 & 0 & 0.02 & 337 & -37 & 0.09 & 359 & -4 & 0.02 & 213 & 6 & 0.06 & 4 & 3 & 0.07 \\
\hline \multirow[t]{2}{*}{900} & 273 & 7 & 0.22 & 359 & 0 & 0.01 & 312 & -47 & 0.09 & 359 & -4 & 0.02 & 224 & 3 & 0.05 & 3 & 3 & 0.05 \\
\hline & \multicolumn{5}{|c|}{$332 \mathrm{~B}-36-5,120-122 \mathrm{~cm}$} & \multicolumn{7}{|c|}{$332 \mathrm{~B}-37-1,126-128 \mathrm{~cm}$} & \multicolumn{6}{|c|}{$332 \mathrm{~B}-37-2,43-45$} \\
\hline \multirow{2}{*}{$\begin{array}{c}\text { Field } \\
\text { (peak oe) }\end{array}$} & \multicolumn{3}{|c|}{ NRM } & & IRM & & & NRM & & & IRM & & & NRM & & & IRN & \\
\hline & $D$ & $I$ & $J / J_{O}$ & $D$ & $I$ & $J / J_{O}$ & $D$ & $I$ & $J / J_{O}$ & $D$ & $I$ & $J / J_{O}$ & $D$ & $I$ & $J / J_{O}$ & $D$ & $I$ & $J / J_{O}$ \\
\hline NRM & 213 & -4 & 1.00 & 356 & 3 & 1.00 & 292 & -8 & 1.00 & 180 & -2 & 1.00 & 308 & -38 & 1.00 & 1 & -5 & 1.00 \\
\hline 25 & 213 & -4 & 1.00 & 355 & 3 & 0.97 & 292 & -9 & 0.99 & 180 & -1 & 0.88 & 307 & -39 & 1.00 & 1 & -5 & 0.93 \\
\hline 50 & 213 & -4 & 0.99 & 356 & 3 & 0.91 & 292 & -10 & 0.94 & 180 & -1 & 0.72 & 307 & -39 & 1.00 & 1 & -5 & 0.77 \\
\hline 100 & 213 & -4 & 0.94 & 356 & 3 & 0.75 & 292 & -13 & 0.71 & 180 & -1 & 0.40 & 306 & -39 & 0.82 & 1 & -5 & 0.46 \\
\hline 150 & 212 & -5 & 0.81 & 356 & 3 & 0.58 & 292 & -17 & 0.48 & 180 & -1 & 0.21 & 305 & -39 & 0.57 & 1 & -5 & 0.27 \\
\hline 200 & 211 & -6 & 0.61 & 355 & 3 & 0.43 & 291 & -20 & 0.31 & 180 & -2 & 0.12 & 306 & -39 & 0.39 & 1 & -5 & 0.17 \\
\hline 250 & 210 & -8 & 0.45 & 366 & 4 & 0.31 & 292 & -22 & 0.21 & 180 & -2 & 0.07 & 306 & -39 & 0.27 & 1 & -4 & 0.10 \\
\hline 300 & 211 & -8 & 0.32 & 355 & 4 & 0.23 & 290 & -22 & 0.14 & 180 & -1 & 0.05 & 306 & -39 & 0.18 & 1 & -4 & 0.07 \\
\hline 400 & 201 & -13 & 0.17 & 355 & 4 & 0.13 & 292 & -19 & 0.09 & 180 & -1 & 0.04 & 304 & -41 & 0.09 & 1 & -4 & 0.04 \\
\hline 600 & 184 & -13 & 0.06 & 356 & 4 & 0.05 & 282 & -17 & 0.05 & - & - & - & 298 & -26 & 0.03 & 0 & -5 & 0.01 \\
\hline 750 & 201 & -16 & 0.04 & 354 & 5 & 0.03 & 263 & -23 & 0.05 & - & - & - & 320 & -43 & 0.02 & 2 & -3 & 0.01 \\
\hline 900 & 238 & -28 & 0.02 & 359 & 1 & 0.02 & 336 & -14 & 0.01 & - & - & - & 275 & 18 & 0.02 & 0 & 6 & 0.01 \\
\hline & & & 35-6-1, & 39-91 & & & & & $36-5-2$ & $5-7 \mathrm{~cm}$ & & & & & & & & \\
\hline Field & & NRM & & & IRM & & & NRM & & & IRM & & & & & & & \\
\hline (peak oe) & $D$ & I & $J / J_{O}$ & $D$ & $I$ & $J / J_{O}$ & $D$ & $I$ & $J / J_{O}$ & $D$ & $I$ & $J / J_{O}$ & & & & & & \\
\hline NRM & 275 & -60 & 1.00 & 184 & -1 & 1.00 & 341 & -66 & 1.00 & 180 & 0 & 1.00 & & & & & & \\
\hline 25 & 274 & -60 & 1.00 & 184 & -1 & 0.98 & 341 & -66 & 1.00 & 180 & 0 & 0.99 & & & & & & \\
\hline 50 & 273 & -60 & 0.98 & 184 & -1 & 0.91 & 340 & -66 & 0.99 & 180 & 0 & 0.96 & & & & & & \\
\hline 100 & 271 & -60 & 0.91 & 184 & -1 & 0.75 & 340 & -66 & 0.98 & 180 & 0 & 0.88 & & & & & & \\
\hline 150 & 269 & -60 & 0.85 & 184 & -1 & 0.61 & 340 & -66 & 0.95 & 180 & 0 & 0.78 & & & & & & \\
\hline 200 & 268 & -60 & 0.76 & 184 & -1 & 0.50 & 340 & -65 & 0.89 & 180 & 0 & 0.68 & & & & & & \\
\hline 250 & 268 & -50 & 0.55 & 184 & -1 & 0.40 & 340 & -65 & 0.80 & 180 & 0 & 0.58 & & & & & & \\
\hline 300 & 266 & -60 & 0.56 & 184 & -2 & 0.33 & 340 & -65 & 0.71 & 180 & 0 & 0.50 & & & & & & \\
\hline 400 & 266 & -59 & 0.43 & 184 & -2 & 0.24 & 340 & -65 & 0.55 & 180 & 0 & 0.37 & & & & & & \\
\hline 600 & 271 & -60 & 0.23 & 184 & -1 & 0.13 & 344 & -67 & 0.29 & 180 & -1 & 0.20 & & & & & & \\
\hline 750 & 269 & -56 & 0.18 & 184 & -1 & 0.10 & 321 & -65 & 0.18 & 180 & 0 & 0.15 & & & & & & \\
\hline 900 & 254 & -71 & 0.10 & 184 & -2 & 0.07 & 346 & -69 & 0.13 & 180 & -1 & 0.10 & & & & & & \\
\hline
\end{tabular}

of an SP fraction, as discussed earlier. The high-field hysteresis loops show a $J_{r} / J_{\max }$ value of 0.2 at $20^{\circ} \mathrm{C}$, increasing to 0.6 at $-196^{\circ} \mathrm{C}$ along with an order-ofmagnitude increase in $H_{c}$. These increases seem to reflect passage of the material through the Verwey transition, indicating SD magnetite or titanomagnetite as the main carrier; this conclusion is compatible with the same material being largely superparamagnetic at $20^{\circ} \mathrm{C}$. Possibly the increased size of the hysteresis loop at $20^{\circ} \mathrm{C}$ after heating and the irreversible features of the $k-T$ and $M-T$ curves all can be explained by conversion of SP into SD particles due to grain growth or oxidation during heating.

"Type I" behavior very similar to that described above was observed in Leg 34 basalts (Deutsch and Put- zold, 1975), where the majority of the samples produced Rayleigh loops which were explained on the SP model; they showed an excellent one-to-one correlation with $k-T$ curves and high-field hysteresis loops of the kind shown in Figure 2.

A polished section made of this sample was observed under an optical microscope (up to $\times 1000$ ) showing that coarse magnetite or titanomagnetite grains with diameters of several hundred microns, typically $\sim 300$ $\mu \mathrm{m}$, are ubiquitous, though (titano)magnetite grains down to a few microns in size were also found. This finding is similar to that of Ade-Hall and Johnson (1975), who observed characteristically coarse-grained (titano)magnetite in Leg 34 basalts yielding Type I properties. At first sight these results seem to call for 


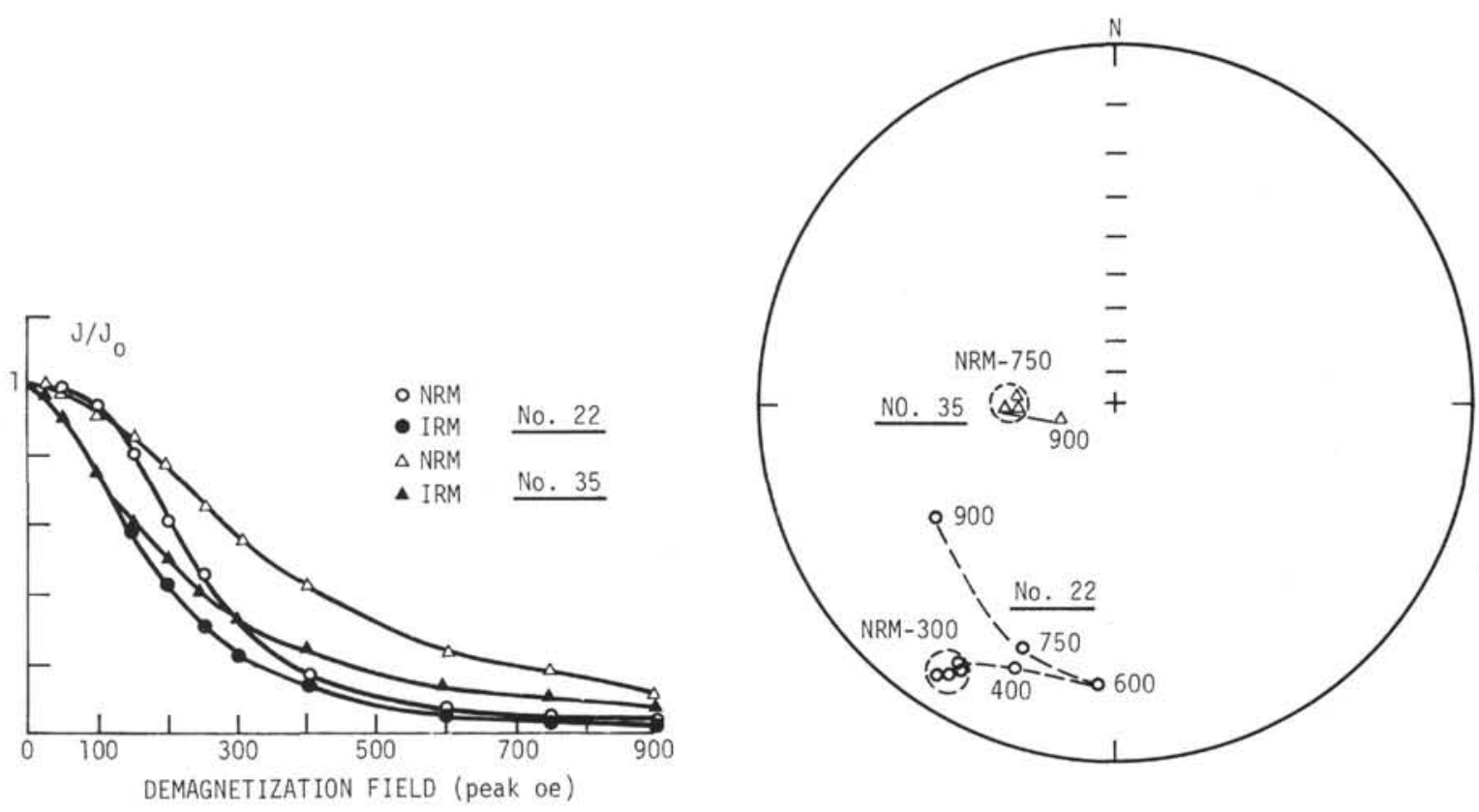

Figure 1. Left. Normalized AF demagnetization curves of natural remanence and of saturation isothermal remanence produced in a field of 8600 oe for Samples 22 (332B-36-5, 120-122 cm) and 35 (335-6-1, $89-91 \mathrm{~cm})$. Right. Directional changes of NRM of the two samples during AF demagnetization plotted on a Wulff's net.

linking of observed VRM and other Type I properties in basalts with multidomain (MD) structure, as indeed several authors have done. Against this we argue that the entire SP-SD range is suboptical, so that interpretation of domain structure based on optical (probably even electron) microscopy can be misleading: microscope studies cannot rule out the possible presence of very fine subdivisions in the observed coarse magnetite grains, or of single-domain grains or both. We conclude that the SP model favored by us in explaining the "Type I" properties of Sample 332B-11-1 is not contradicted by the optical findings.

The $k$ peak in Figure 2a constitutes a susceptibility enhancement analogous to Dunlop's (1974) mechanism where high-temperature Hopkinson peaks point to deep-seated induced anomaly sources. In Leg 37 basalts, with only one sample of this type found, this effect is probably unimportant.

\section{Sample 334-26-2 (Figure 3)}

This sample gave strikingly different results from the sample previously discussed. The $k-T$ curve clearly indicates multidomain magnetite (Radhakrishnamurty and Deutsch, 1974), showing near-reversibility, an abrupt drop of $k$ at the Curie temperature, and a peak near the Verwey transition $\left(-155^{\circ}\right)$ that would be suppressed in single-domain magnetite due to shape anisotropy. The $M-T$ curve, being obtained on a powder instead of the disc used in $k-T$ experiments, indicates oxidation of original magnetite (titanomagnetite) to hematite, with higher $T_{c}\left(630^{\circ} \mathrm{C}\right)$ and a depressed cooling curve. This is also consistent with an original large-grain or multidomain state (Feitknecht and Gallager, 1970). There is no Rayleigh loop and the high-field loops at $20^{\circ} \mathrm{C}$ and $-196^{\circ} \mathrm{C}$ are very similar. However, both $H_{c}$ and $J_{r} / J_{\max }$ of purely multidomain magnetite (titanomagnetite) should be very small at either temperature, though larger at $-196^{\circ} \mathrm{C}$, whereas stoichiometric single-domain magnetite would have produced at room temperature a loop with $J_{r} / J_{\max }$ of 0.5 and at $-196^{\circ} \mathrm{C}$ a loop similar to that in Figure $2 \mathrm{c}$ (middle diagram). Thus the $k-T$ curves and the hysteresis loops indicate that this sample probably contains MD magnetite as well as strongly cation-deficient SD or PSD magnetite. After heating (Figure 3, bottom), $H_{c}$ increased moderately, probably due to some oxidation.

\section{"Type II" Behavior}

The $k-T$ curves on 11 additional samples (Table 1) are different from the "SP" and "MD" curves (Figures $2 \mathrm{a}, 3 \mathrm{a})$ by peaking initially at intermediate temperatures $\left(\sim 200^{\circ}-500^{\circ} \mathrm{C}\right)$ and by their pronounced irreversibility. Despite large sample-to-sample variations in the location and height of the $k$ peaks, two main kinds of heating curves appear: In Samples 332B$37-2,102-105 \mathrm{~cm}$ (Figure 4a) and 332B-42-1, 13-15 cm, $k$ rises continuously to a single broad peak near $450^{\circ} \mathrm{C}$, while Figure 4a (Sample 335-6-1, 105-107 cm) typifies heating curves having two main peaks, shown also by Samples 332B-22-4, 48-50 cm; 332B-35-2, 91-94 cm; $332 \mathrm{~B}-35-3,28-31 \mathrm{~cm} ; 334-20-1,114-116 \mathrm{~cm} ; 335-6-1$, $112-114 \mathrm{~cm}$; and 335-6-1, 129-131 cm (Table 1), though not all these have a split peak at high temperature.

Type IIa: A grouping into Subtypes IIa and IIb, based on relatively smaller and larger $k$ values measured by Rayleigh-loop tracer, was noted earlier. For Type IIa samples, the high-field hysteresis loops at room temperature typically (Figure 4c, bottom, upper loop) showed large $H_{c}$ and $J_{r} / J_{\max }$ ratios close to 0.5 , indicating SD magnetite or titanomagnetite, with both $H_{\mathrm{o}}$ and $J_{r} / J_{\max }$ increasing substantially below the Verwey 
transition (lower loop). The pronounced irreversibility shown by the $k-T$ and $M-T$ heating-cooling curves, and the upswing of the $k-T$ cooling curve with decrease in temperature below $0^{\circ} \mathrm{C}$, all suggest that relatively unoxidized SD material (as indicated by the hysteresis loops) has become (more) cation-deficient due to heating (Radhakrishnamurty and Deutsch, 1974, figure 3).
Type IIb: Behavior similar to that shown in Figure 4 was observed in most other samples studied by us, except for the following cases: Samples 332B-35-1, 4-7 $\mathrm{cm} ; 332 \mathrm{~B}-35-4,23-30 \mathrm{~cm} ; 332 \mathrm{~B}-37-1,126-128 \mathrm{~cm} ; 332 \mathrm{~B}-$ $37-2,102-105 \mathrm{~cm}$; and $334-26-2,4-7 \mathrm{~cm}$ showed very little change in their hysteresis behavior when cooled to liquid nitrogen temperature. Similar cases of apparent
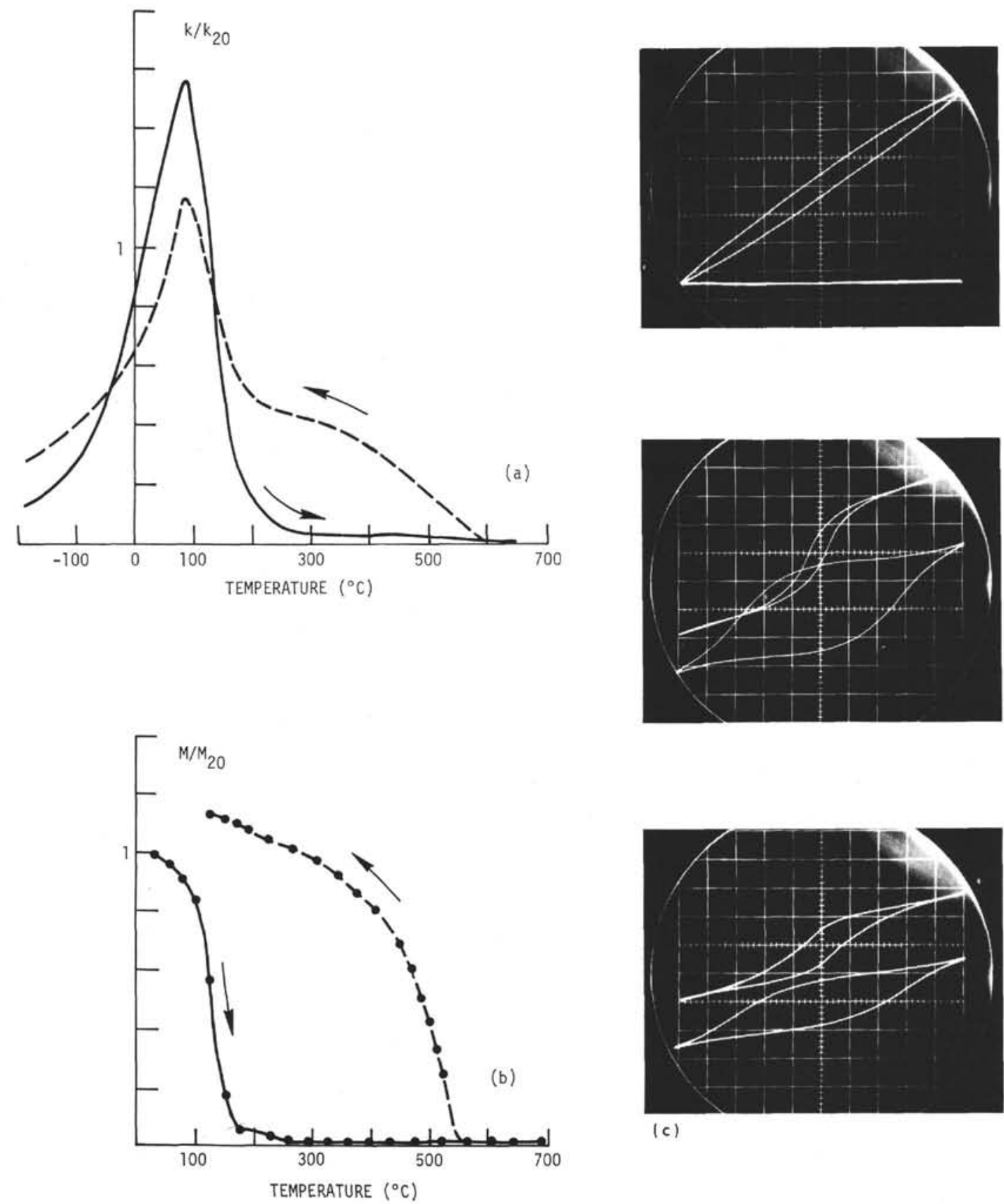

(c)

Figure 2. Sample 332B-11-1, 110-112. (a) Normalized susceptibility versus temperature (k-T curve) in 0.31 oe, heating and cooling. (b) Normalized magnetic moment versus temperature (M-T curve) in 1300 oe, heating and cooling. M-T rather than $\mathrm{J}_{\mathrm{S}}-\mathrm{T}$ is quoted as this field is not always sufficient for saturation. (c)Top: Photograph of Rayleigh loop in 10 peak oe, with horizontal reference trace. Center: Photograph of hysteresis loops in 1200 peak oe of a fresh sample portion at $20^{\circ} \mathrm{C}$ (upper trace) and $-196^{\circ} \mathrm{C}$ (lower trace). Bottom: Same as center diagram, measure on sample following $\mathrm{k}-\mathrm{T}$ experiment. 

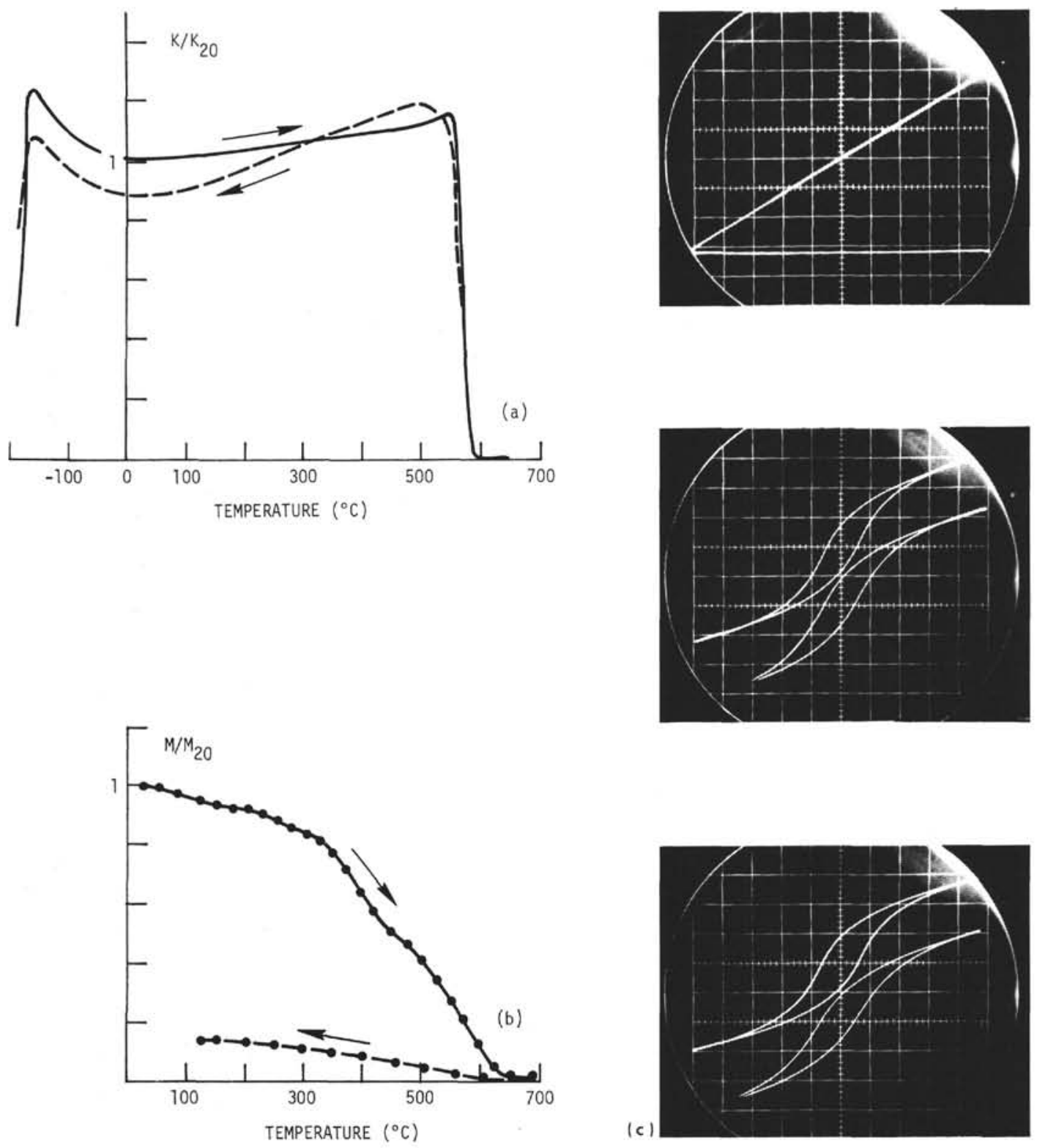

Figure 3. Sample 334-26-2, 4-7. (a), (b), (c) as in Figure 2.

absence of the Verwey transition in magnetite have been noted in high-field hysteresis experiments with basalts by Radhakrishnamurty et al. (1971) and an explanation in terms of cation-deficiency has been proposed (Radhakrishnamurty and Deutsch, 1974, fig. $2 b)$. Figure 1 shows the results of some of the experiments performed on Sample 332B-37-2, 102-105 $\mathrm{cm}$. The presence of a cation-deficient phase is suggested also by the shape of the $k-T$ heating curve, in particular by the decrease in susceptibility as the sample is heated from $-196^{\circ} \mathrm{C}$ to room temperature. The large slope of the low-field hysteresis trace is evident.

\section{SUMMARY AND CONCLUSIONS}

We have conducted two types of tests on Leg 37 basalts to infer the domain state of the magnetic minerals contained. The first one involved a measure of the bulk magnetic properties of the rock and included both the susceptibility and hysteresis measurements. The second approach involved a study of the remanence carriers through the Lowrie-Fuller test. Not surprisingly, the Lowrie-Fuller study and most of the hysteresis measurements indicated that the remanence carriers of the samples are of a single-domain nature. On the other hand, low-field susceptibility measurements tend to show up preferentially any magnetic instability, and for this reason the $k-T$ curves sometimes indicated different bulk magnetic properties from those inferred on the basis of hysteresis measurements. These apparently conflicting results can be reconciled only by invoking the presence in these basalts of mixtures of grains.

With a single exception, where an MD magnetite fraction was clearly indicated, the magnetic carrier in these samples was identified as pure or cation-deficient single-domain magnetite or titanomagnetite. One sam- 

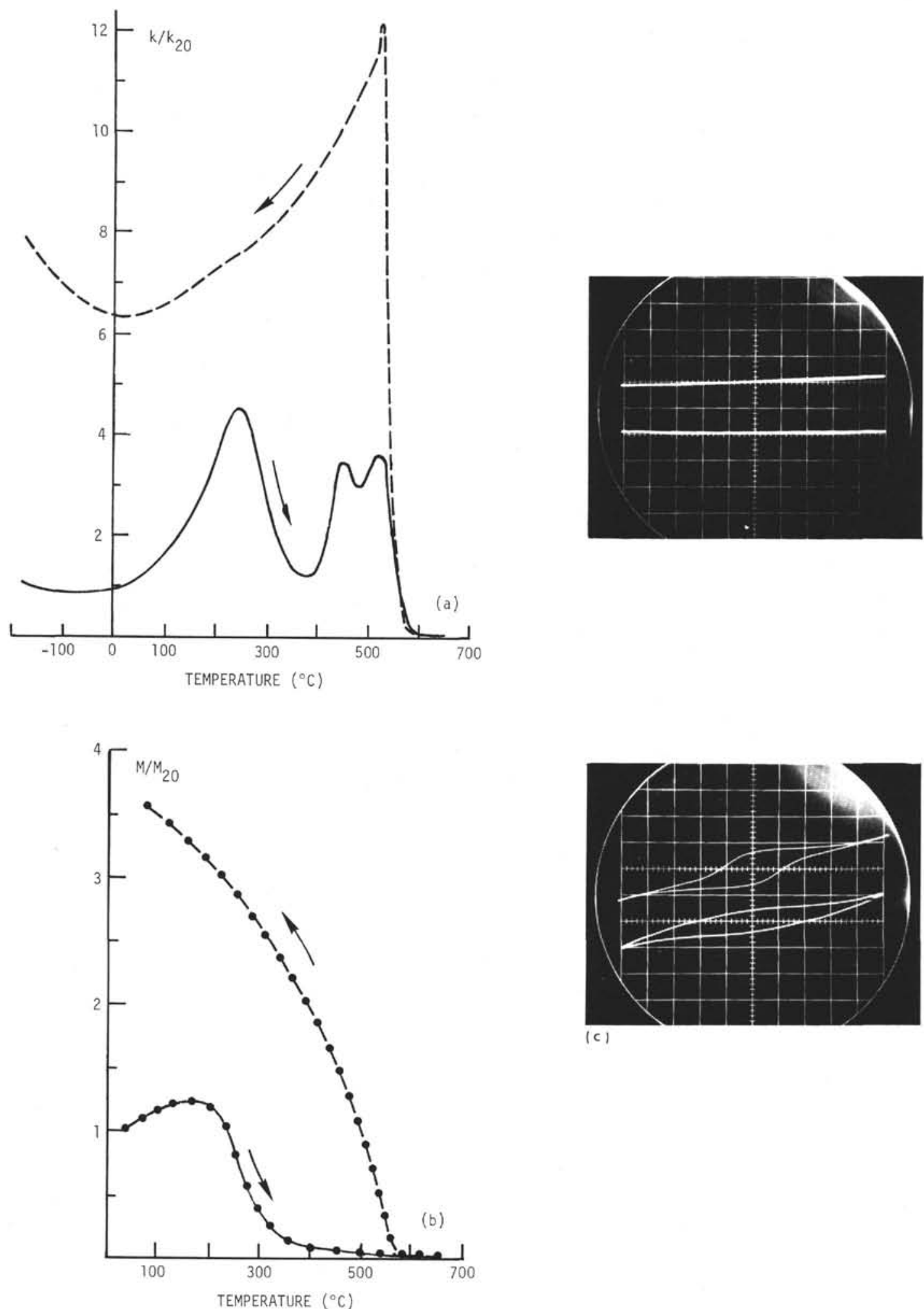

(c)

Figure 4. Sample 335-6-1, 105-107 cm. (a), (b) as in Figure 3a, b. (c) Top: Photograph o, Rayleigh loop in 10 peak oe, with horizontal reference trace. Bottom: Photograph of hysteresis loops in 1200 peak oe of fresh sample at $20^{\circ} \mathrm{C}$ (upper trace) and $-196^{\circ} \mathrm{C}$ (lower trace).

ple only showed behavior attributable to grains in the superparamagnetic size range.

\section{ACKNOWLEDGMENTS}

We benefited greatly from discussions with Dr. D.J. Dunlop, Toronto, and Dr.C. Radhakrishnamurty, Bombay. This work was supported by the National Research Council of Canada through a DAGS Grant to G.S. Murthy and through Operating Grant A-1946 to E.R. Deutsch.

\section{REFERENCES}

Ade-Hall, J.M. and Johnson, H.P., 1975. Rock magnetism of basalts, Leg 34. In Hart, S.R., Yeats, R.S., et al., Initial Reports of the Deep Sea Drilling Project, Volume 34: 

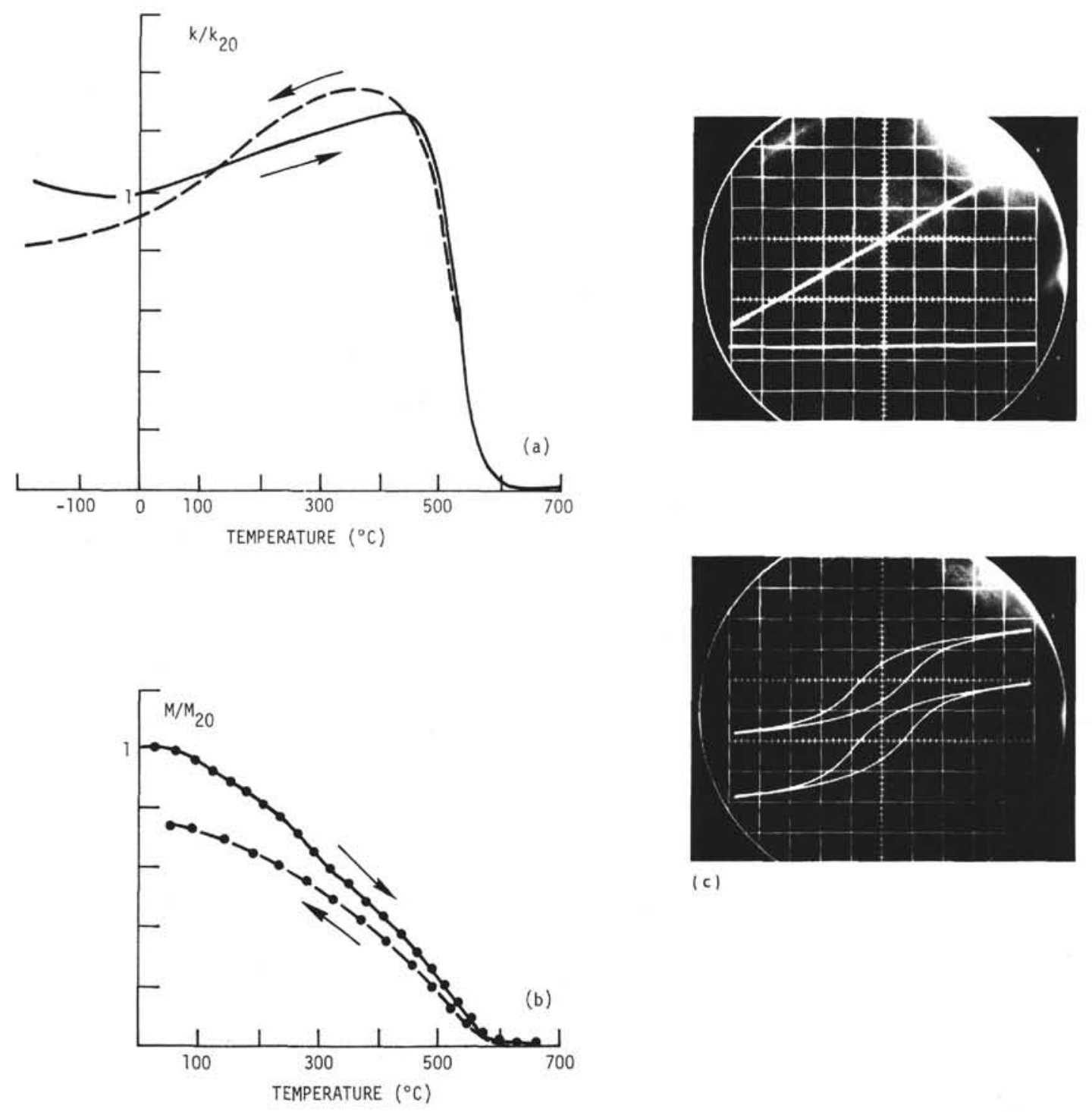

(c)

Figure 5. Sample 332B-37-2, 102-105 cm. (a), (b), (c) as in Figure 4.

Washington (U.S. Government Printing Office), p. 459468.

Bean, C.P., 1955. Hysteresis of mixtures of ferromagnetic micropowders: J. Appl. Phys., v. 26, p. 1381-1383.

Bickford, L.R., Jr., 1950. Ferromagnetic resonant absorption in magnetite single crystal: Phys. Rev., v. 78, p. 449-457.

Deutsch, E.R., Kristjansson, L.G., and May, B.T., 1971. Remanent magnetism of lower Tertiary lavas on Baffin Island: Canadian J. Earth Sci., v. 8, p. 1542-1552.

Deutsch, E.R. and Pätzold, R.R., 1975. Magnetic properties and domain state of basalt cores from the Nazca plate. In Hart, S.R., Yeats, R.S., et al., Initial Reports of the Deep Sea Drilling Project, Volume 34: Washington (U.S. Government Printing Office), p. 501-512.

Dunlop, D.J., 1969. Hysteretic properties of synthetic and natural monodomain grains: Phil. Mag., v. 19, p. 329338.

1974. Thermal enhancement of magnetic susceptibility: J. Geophys./Zeits. Geophys., v. 40, p. 439-451.

Feitknecht, W. and Gallagher, K.G., 1970. Mechanism for the oxidation of $\mathrm{Fe}_{3} \mathrm{O}_{4}$ : Nature, v. 228, p. 548-549.

Johnson, H.P., Lowrie, W., and Kent, D.V., 1975. Stability of anhysteretic remanent magnetization in fine and coarse magnetite and maghemite particles: Geophys. J. Royal Astron. Soc., v. 41, p. 1-10.
Likhite, S.D., Radhakrishnamurty, C., and Sahasrabudhe, P.W., 1965. Alternating current electromagnet type hysteresis loop tracer for minerals and rocks: Rev. Sci. Inst., v. 36, p. 1558-1560.

Lowrie, W. and Fuller, M., 1971. On the alternating field demagnetization characteristics of multidomian thermoremanent magnetization in magnetite: J. Geophys. Res., v. 76 , p. 6339-6349.

Morrish, A.H. and Watt, L.A.K., 1958. Coercive force of iron oxide micropowders at low temperatures: J. Appl. Phys., v. 39, p. 1029-1033.

Néel, L., 1955. Some theoretical aspects of rock magnetism: Adv. Phys., v. 4, p. 191-243.

1970. Interpretation des cycles d'hystérésis entranglés de certaines basalts: C. R. Hebd. Séanc. Acad. Sci. Paris, v. 270, p. 1125-1130.

Pätzold, R.R., 1972. High temperature magnetic susceptibility bridge: M.Sc. Thesis, Memorial University of Newfoundland.

Radhakrishnamurty, C. and Deutsch, E.R., 1974. Magnetir techniques for ascertaining the nature of iron oxide grain: in basalts: J. Geophys./Zeits. Geophys., v. 40, p. 453-465.

Radhakrishnamurty, C. and Sastry, N.P., 1970. A singledomain grain model for the low field constricted hysteresis 
loops of some basaltic rocks: Indian Acad. Sci. Proc., v. 72, p. $94-102$.

Radhakrishnamurty, C., Likhite, S.D., and Sahasrabudhe, P.W., 1969. Some curious magnetic properties of rocks: Palaeogeophysics: New York (Academic Press), p. 223234.
Radhakrishnamurty, C., Likhite, S.D., Raja, P.K.S., and Sahasrabudhe, P.W., 1971. Magnetic grains in Bombay columnar basalts: Nature Phys. Sci., v. 235, p. 33-35.

Radhakrishnamurty, C., Raja, P.K.S., Likhite, S.D. and Sahasrabudhe, P.W., 1972. Problems concerning the magnetic behaviour and determination of Curie points of certain basalts: Pure Appl. Geophys., v. 93, p. 129-140. 